\title{
ABNORMALITIES OF THE DEEP VEINS OF THE LEG
}

\author{
By F. B. CocketT, M.S., F.R.C.S.
}

St. Thomas's Hospital, London

The anatomy and pathology of the venous system of the leg has been, until very recently, a neglected subject. This is so, in spite of the fact that lesions resulting from diseases of these veins are among the commonest from which mankind suffers. To Homans (1917) must go the credit for awakening renewed interest in the subject, for he first clearly showed that the distressing "ulcer and induration' syndrome of the lower leg was a sequel to thrombosis of the deep veins; he also first showed that recanalization of these thrombosed deep veins occurred in many cases. On the subject of anatomy and physiology of the veins of the leg, Gay's work in 1867 , and later the painstaking studies of Turner Warwick (193I), gave a clear picture, although both authors received little attention at the time. During the last ten years, with the advent of safe techniques of venography, radioactive isotopes and accurate methods of measuring venous pressure in the veins of the foot, the growth of knowledge has been fast.

In this article we will consider first the normal anatomy of the deep veins, secondly the physiology of venous return from the leg and thirdly how the effects of disease of the deep veins modifies the venous return and produces certain lesions and symptoms.

\section{Normal Anatomy}

Whereas the anatomy of the arteries is relatively constant, this is not so with the veins. Although the basic pattern of venous anatomy is constant one must be prepared for endless variations and duplications. These are part of normal anatomy and this variation in normal anatomy from patient to patient is the reason for many of the difficulties both in interpretation of venograms and in operations upon the veins. A knowledge of the basic pattern and the normal variations is therefore essential to interpret, diagnose and treat the effects of venous incompetence.

Fig. I shows the anatomy of the venous drainage of the calf and Fig. 2 shows the same thing in diagrammatic form.

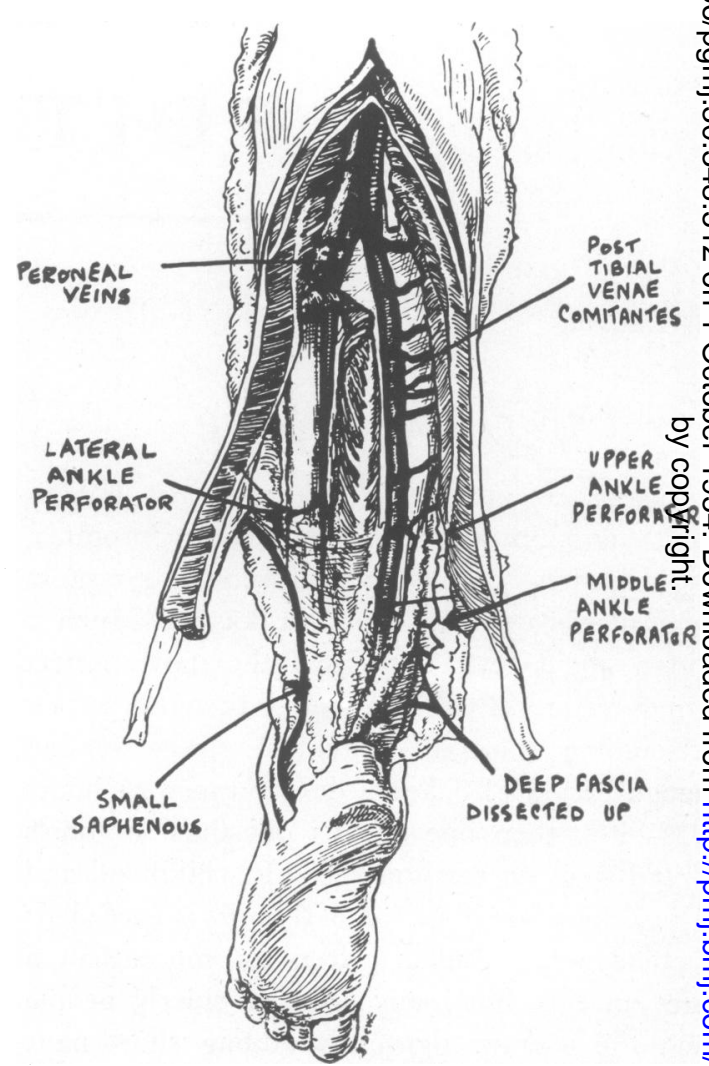

FIG. 1.-Dissection showing the anatomy of the venous drainage of soleus and the deep veins of the legs Note particularly: (I) The relation of the ank perforating veins, where they join the deep veins to the muscular veins from soleus. (2) The peroneas vein takes little part in the venous drainage of the lower half of soleus.

The venous drainage of the soleus and gastroc? nemius muscles, which constitute most of the calfo is very different.

\section{Soleus}

The soleus muscle has a series of large venou串 sinuses within it which are devoid of valves. These 


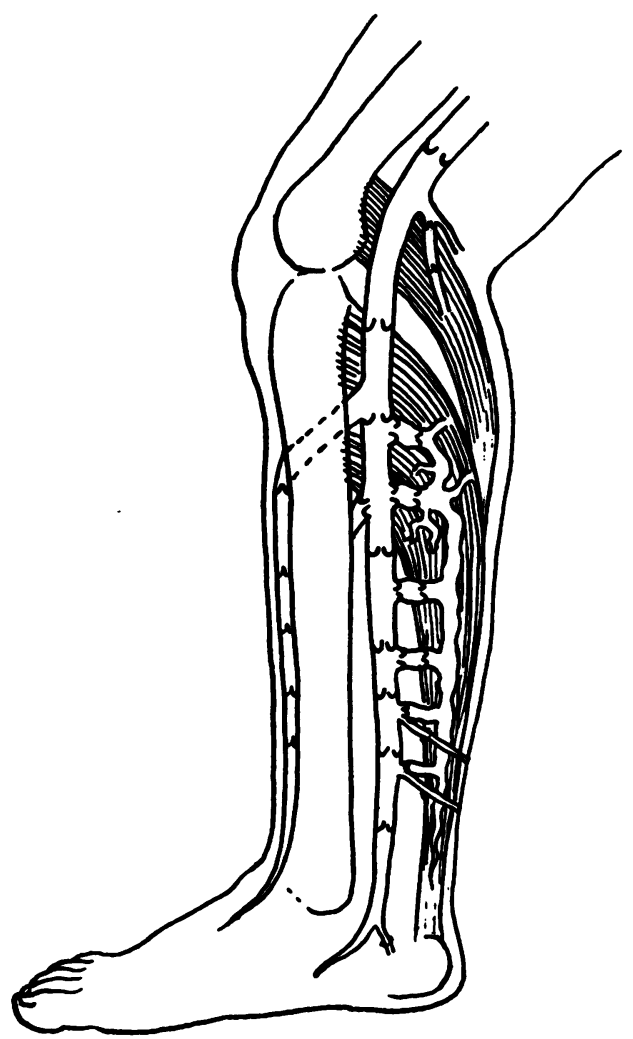

Fig. 2.-This diagram illustrates: (I) The difference in the venous drainage of soleus and gastrocnemius. (2) The arrangement and profusion of venous valves in the leg veins. (Note that the venous sinus within soleus is devoid of valves.)

venous sinuses differ from subject to subject in their size and degree of development and they are of importance, as it is in them that calf thrombosis starts. They drain by a series of short but lax veins into the posterior tibial and peroneal veins as shown. This series of short lax veins are large and are grouped closer together in the upper part of the calf and in the position of rest assume a tortuous appearance; this tortuosity, occasionally seen on venograms, is sometimes mistakenly called ' deep varicose veins,' but this appearance is, in fact, normal here.

The venous drainage of the lower half of soleus is interesting and significant when we come to consider the genesis of post-thrombotic ulcers. Firstly, it will be observed in Fig. I that nearly the whole venous drainage of the lower half of the calf goes into the posterior tibial vein. The peroneal vein is quite small in the lower third of the leg and runs deep to the flexor hallucis longus origin from the fibula, close up against the interosseous membrane. In this region it receives one fairly constant

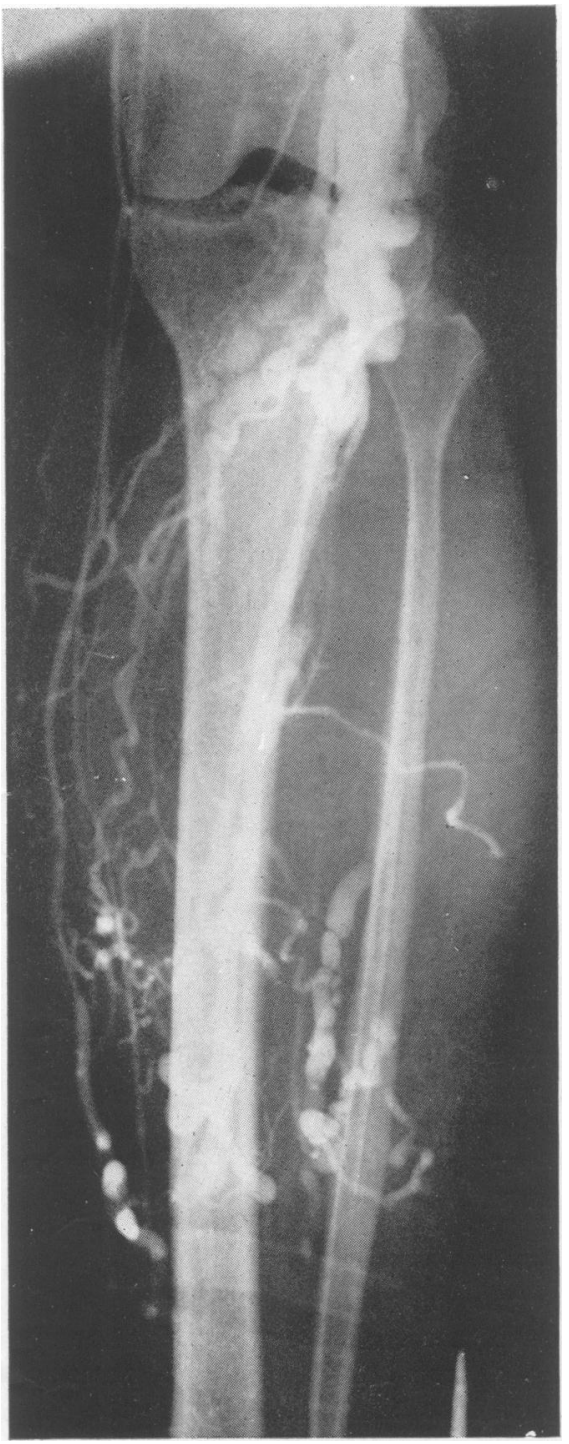

Fig. 3.-Deep Varicose Veins. The tortuous dilated veins seen in the upper part of this venogram are the dilated gastrocnemial veins.

large lateral perforating vein (see Figs. I and 7). This vein as it winds round the fibula receives a branch from the soleus. This represents the only contribution from soleus in this region. In the upper half of the leg the peroneal vein emerges from under the flexor hallucis belly to lie in the posterior compartment and here it receives several large lax veins from the lateral aspect of soleus which rapidly convert into quite a large vein before it unites with the posterior tibial to form, the popliteal.

Now turning to the posterrior tibial veins in the 


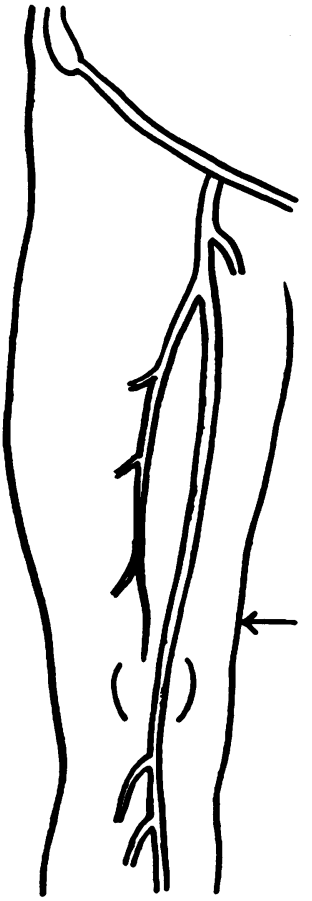

(a)

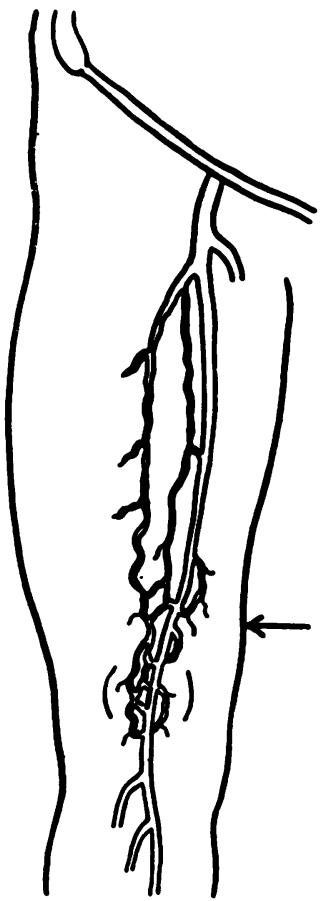

(b)

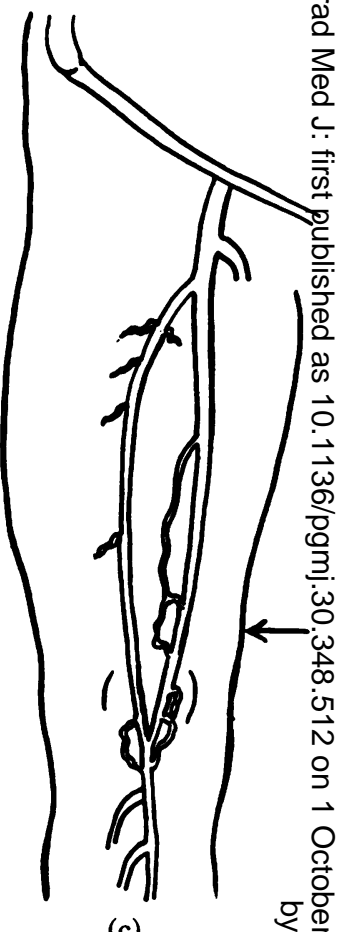

(c)

FIG. 4. - The arrow represents the level of the adductor canal. For further description see text.

lower third, it will be observed that where these veins receive the two lowest muscular veins from soleus they also receive two large perforating veins which perforate the deep fascia of the leg and drain the subcutaneous tissues of the internal malleolar region (the ulcer and induration area). This anatomical arrangement (see Figs. I, 2 and 6) is the key to appreciating two things: (I) That there is a direct anatomical pathway for the spread of thrombus from calf sinuses to posterior tibial veins and then either outwards in the perforators and/or upwards in the posterior tibial veins. (2) The reason why the site of election for the cutaneous sequelae of deep thrombosis is so often the inner side of the leg in the malleolar region and not the outer side.

\section{Gastrocnemius}

Each belly of gastrocnemius is drained by a single large vein or pair of venae comitantes which enter the popliteal vein in the lower part of the popliteal fossa. These veins are often seen on venograms of the region, are easily picked out and are accompanied by an artery and a nerve. When the vales of the popliteal and femoral veins are destroyed by the process of deep thrombosis and recanalization these veins are subjected to an increased venous pressure and sometimes dilate and become tortuous and varicose, constituting type of true deep varicose veins (Fig. 3).

\section{The Popliteal and Femoral Veins}

The anatomy of the popliteal and femoral veins is shown in Fig. 4; (a) represents the basic pattern $\overrightarrow{\vec{D}}$ it is in fact most unusual for the popliteal and femoral veins to be represented by one single large trunk as depicted in most anatomy books; (b $\overrightarrow{\text { P. }}$ represents a much commoner state of affairs wheres there is a main channel with numerous venae comitantes; these venae comitantes are usuallo closely applied to the accompanying artery and inter-communicate in a plexiform manner. Thus the popliteal and femoral veins show every con ceivable variation from, on the one hand, fairly isolated single large channels (as depicted in text books) to, on the other, a plexus of inter-com?. municating venous channels in which one singlef dominant channel can scarcely be picked out. $\mathrm{Re}_{-}^{-}$ duplication of venous channels in the popliteats fossa and Hunter's canal is thus the rule rathefo than the exception. One further point is of im? portance; in the region of the adductor canal the plexus of accompanying venae comitantes is usually particularly profuse and, at this point, an anastomosis with the profunda system takes placec which is very constant. This anastomosis con 


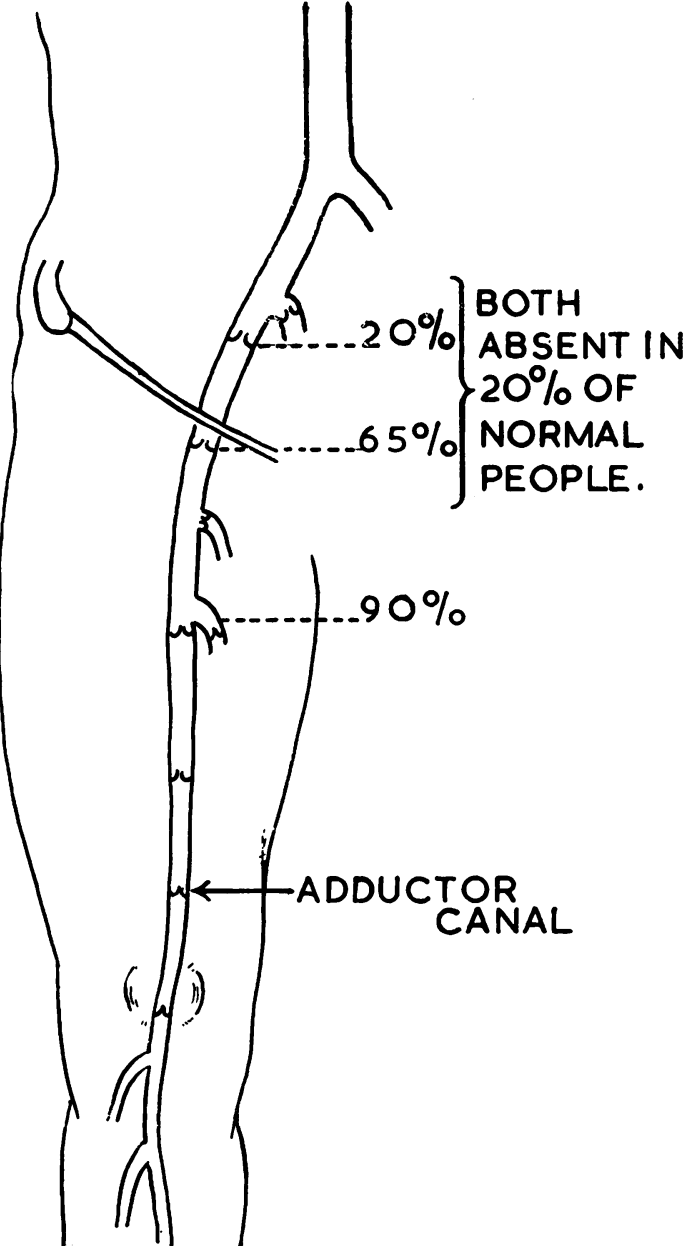

FIG. 5.-Position of valves in the femoral and poplitela veins.

stitutes an important avenue of collateral venous return when the femoral vein is blocked. Finally, Fig. 4 (c) represents a state of affairs found in about 12 per cent. of legs (McLachlin and Paterson, I95I ; Cockett, 1953) where the lower part of the profunda vein is large and unites directly with the popliteal vein or popliteal venous plexus. In such cases the profunda offers a large alternative pathway of venous return from the lower leg.

This variation in venous arrangement and in the number and profusion of available deep collaterals gives some clue to the apparently capricious way in which the symptoms of deep venous obstruction arise and subside in different patients.

\section{The Valves}

The venous valves of the leg veins are profuse and of great importance in the pump mechanism whereby blood is returned to the heart against gravity in the upright position. In the venous sinuses of the soleus there are no valves, but in all the muscular veins draining both soleus and gastrocnemius into the deep veins, valves are numerous. The posterior tibial and peroneal veins are profusely valved, having a pair of valves about every inch. In addition all the perforating veins in the lower part of the calf and all the veins connecting the deep with the superficial veins in all parts of the leg, are so valved that blood can only pass from superficial to deep veins and reflux outwards from the deep to the superficial is prevented normally.

The arrangement of valves in the large venous trunks, the popliteal, femoral, common femoral and iliac veins is important in considering the aetiology of both superficial varicose veins and deep venous incompetence. The arrangement has been studied by Eger and Casper (1943), Powell and Lynn (1 95 I), Bazmajian (I952) and Cockett (1953). The findings are summarized in the diagram (Fig. 5).

The diagram shows the average sites where valves are to be found. However, once again there is considerable variation from case to case and the variations must be known as they constitute normal anatomy. In about 20 per cent. of cases no valve is to be found between the heart and the entry of the great saphenous vein. This may be of significance in the aetiology of incompetence of the great saphenous system. In 20 per cent. of people there is a valve in the external iliac and in about 65 per cent. of people there is a valve in the common femoral. The most constant valve is that which occurs just below the entry of the profunda vein. There is usually another valve about the mid-point of Hunter's canal and another in the popliteal vein. However, the number of valves in the segment of deep vein from inguinal ligament to popliteal may vary from two to nine. Occasional cases are recorded (Bazmajian, 1952; Luke, I95 I) of congenital absence of valves in this entire stretch of vein although these are very rare. Even in these cases the valves in the smaller veins are normal.

\section{The Superficial Veins}

The basic pattern of arrangement of the venous drainage of the skin and subcutaneous tissues of the lower leg by the superficial veins must be mentioned in order to understand how lesions of the deep veins may affect the superficial tissues (Figs. 6 and 7).

Figs. 6 and 7 show the venous arrangement on the inner side and outer side of the limb. It will be appreciated that in the erect position the venous drainage of the ulcer bearing area of the ankle is to the deep veins (posterior tibial) by the large fairly 


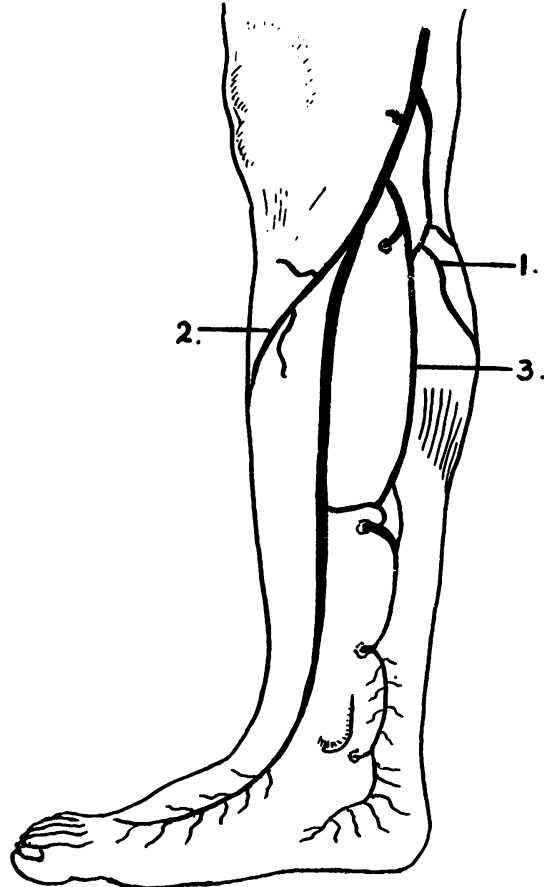

FIG. 6.-This shows the essential anatomy of the venous drainage of the skin and subcutaneous tissue on the inner side of the limb. Note that the area where ulcers commonly occur is drained by the perforating veins shown, and that there is a delicate venous arch connecting these perforating veins. Also note that the saphenous vein itself has few branches below knee level, the main groups of branches ( 1,2 and 3 ) arise at or just below the knee. The branch labelled (3) is constant and important, as it may connect the incompetent saphenous system to the delicate venous arch connecting the perforating veins.

constant perforating veins shown (see venous drainage of soleus). The saphenous system takes little part in the venous drainage of this area in the erect position, although the effects of valvular destruction and incompetence in this system may reach the venous arch connecting the perforating veins via the large posterior branch arising at knee level, shown in the diagram. The perforating veins shown are large fairly constant ones; in addition there are a number of much smaller inconstant, indirect ones scattered over the muscle bellies of the limb.

\section{The Physiology of Venous Return from the Leg}

Thanks to the intensive venographic investigations (Dow, I95I; Linton and Hardy, 1948; Cockett, 1953) and to the studies on venous pressure in the superficial veins and deep veins we have now a fairly clear picture of the venous return

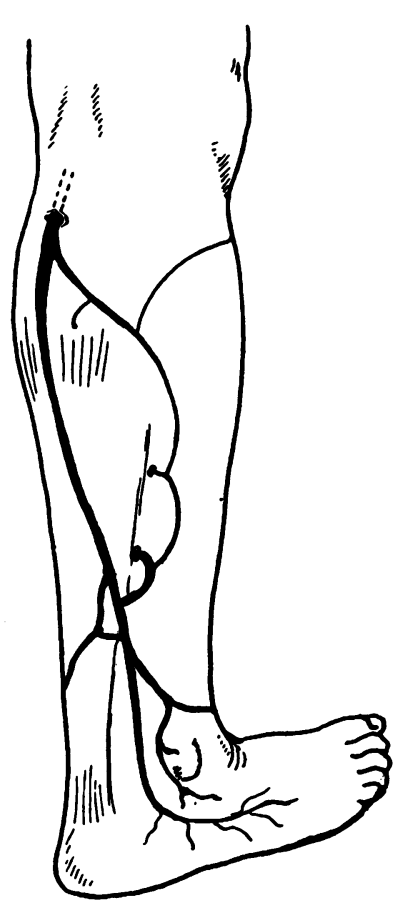

FIG. 7.-Shows the essential venous drainage of thession and subcutaneous tissues on the outer side of the limb. The large perforating vein shown, \&bagt one-third of the way up on the outer side, is yefy constant and usually connects directly witho the small saphenous vein. If both this perforator the small saphenous are incompetent considerale venous hypertension occurs in the subcutaneofs tissues behind the malleoli.

from the lower limb. The soleus is a large powe? ful muscle which, especially in its lower third, 15 contained within a sheath of strong inelastic fascis. This arrangement of a large muscle within a strong inelastic fascial investment means that great rise of pressure occurs within the fascial envelope when the muscle contracts. It is referred to as the ' calf pump.' The actual rise of pressuge within the lower third of the calf pump on contraction is from o to $90 \mathrm{~mm}$. of $\mathrm{Hg}$. (measured by Wells, Youmans and Miller, 1938). Barcroft and Dornhorst (1948) have also shown that this ca्मf pump can overcome a resistance greater tha roo mm. Hg. Thus when the calf pump cos tracts, blood is squeezed out of it with considerablye force in an upward direction, directed centrally and upwards only by the arrangement of the valves. Notice (diagram 8) that the arrangement of a pă of valves in each perforating vein effectively provents the blood being forced outwards into the sulcutaneous tissues as well, at each contraction. 㝏 some extent all the muscles both of foot, leg and thigh assist in this driving of the blood inwargs 
towards the main deep vein, and upwards, when they contract.

Now the veins in the subcutaneous tissues of the leg and foot are also emptied very efficiently into the deep veins, in the erect position, by muscular action, and exactly how this occurs has been the object of several recent studies (Pollack and Wood, 1949; Walker and Longland, 1950; Warren, White and Belcher, 1949; Hojensgard and Sturup, 1949). In a person with a normal venous system the pressure at rest in a subcutaneous vein in the dorsum of the foot is equal to the pressure of a column of blood extending from foot to heart level. This is equivalent to a pressure of between 85 and $90 \mathrm{~mm}$. Hg., according to the height of the individual. As soon as the calf muscles are put into action, however, this pressure rapidly falls to between 0 and $10 \mathrm{~mm}$. $\mathrm{Hg}$. Thus the efficiency with which the subcutaneous veins are drained into the deep by the systole and diastole of the calf pump is truly remarkable. Hojensgard and Sturup moreover (1952), studying simultaneous pressure recordings of veins inside and outside the pump, showed that blood was actively sucked into the deep veins inside the pump during the phase of diastole of the calf, when for a brief space the pressure in the veins within the calf became lower than that in the veins outside (i.e. in the subcutaneous tissues). The routes by which this blood from the skin enters the pump are the large direct perforating veins shown in Figs. 6 and 7 and by many much smaller indirect perforating veins.

Further interesting studies have been made by Payling Wright (1952) on the speed of venous flow in the leg under various conditions, using radioactive sodium as a tracer element. Briefly she found that in the erect position at rest the flow was extremely slow. At rest in the horizontal position the flow was doubled. If the legs and feet were raised about Io degrees then the flow rate was doubled again. These observations have been confirmed using pyelosil and observing its progress in the veins under the screen.

Thus the two most important factors in ensuring a swift venous return from the leg and preventing venous hypertension and venous stasis are (I) exercise of the calf muscles and (2) the position of the leg relative to the heart. The appreciation of these two factors is of supreme importance in the prophylaxis of post-operative or 'stasis' thrombosis in the leg veins, which is such an important and common problem.

\section{Pathology of the Deep Veins}

Lesions of the deep veins may be classified as traumatic and thrombotic.

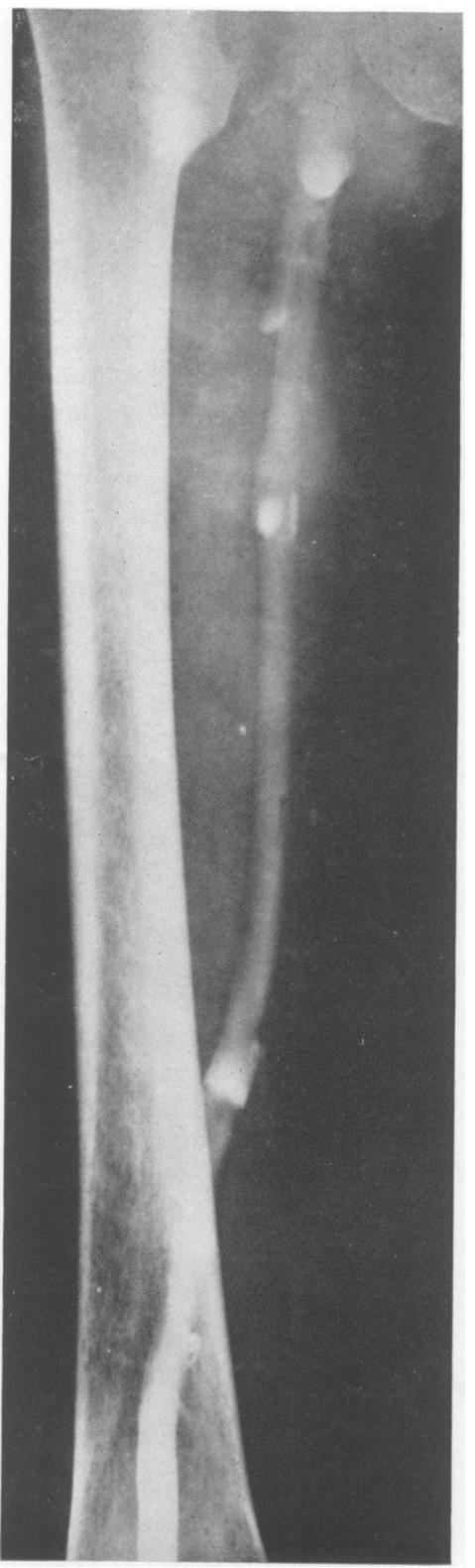

FIG. 8.-This is an ascending venogram of a normal leg, made by the Valsalva technique. Note how the valves show up with the use of the Valsalva manoeuvre. Compare this with Figs. 9, ro and 11.

\section{Traumatic}

Under this heading the effects of surgical ligature of normal deep veins at various levels must be considered. Ligature may be forced upon the surgeon owing to trauma due to external wounding or accidental wounding at operation (the classic example being injury to the common femoral vein during a saphenous ligation operation). The 
effects of such ligatures depend upon the anatomical situation and the availability of collateral channels; a glance at Fig. 4 will help in understanding this. Thus the effect of ligaturing the popliteal or femoral vein distal to the point where the profunda joins it in the upper third of the thigh is slight. Mild oedema lasting a few days only may be expected; after becoming ambulant slight oedema towards the end of the day may be noticed. Ligature of the common femoral between the profunda origin and the inguinal ligament is followed by more severe effects, as is evident from Fig. 4, as far fewer deep venous collaterals are available. More severe oedema of longer standing can be expected. The external iliac vein and the common iliac vein can be ligatured without causing much swelling of the limb, as profuse intrapelvic collateral channels to the other side are available. Ligature of the inferior vena cava, however, as would be expected, is followed by prolonged and severe oedema of both lower limbs, which takes over six months to recede. Usually after ligature of a deep vein it remains patent on both sides of the ligature or at worst a short segmental thrombosis down and up to the next branch of the vein takes place. If, however, more extensive distal thrombosis takes place the sequelae are much more severe and oedema is greater and of longer duration. Thus the aim of treatment after such a ligature must be to try and prevent this extension thrombosis from taking place. The first way to do this is to give every aid to the venous return by simply raising the foot of the bed until all oedema has subsided and by supplying the patient with a firm elastic bandage from toes to knee and encouraging active calf exercises in the early days of ambulation. Ulcers and induration and chronic oedema of the lower leg do not follow such ligatures unless they have been complicated by extensive distal thrombosis or have been actually done for calf thrombosis to prevent embolism.

\section{Thrombosis}

Thrombosis of the deep veins of the leg is common. There are two main varieties. (I) The segmental or ilio femoral thrombosis (see Fig. 9). This thrombosis involves a segment of femoral or iliac vein extending from the vena cava or origin of the internal iliac branch above to a point near to the origin of the profunda femoris. This type of thrombosis usually follows some sort of direct irritation of the vein wall in the vicinity of the pelvis by inflammatory or malignant glands or by a local abscess due to diverticulitis or appendicitis or by gynaecological conditions. The thrombosis may spread retrogradely right down into the calf, when it differs in no way in its symptoms or

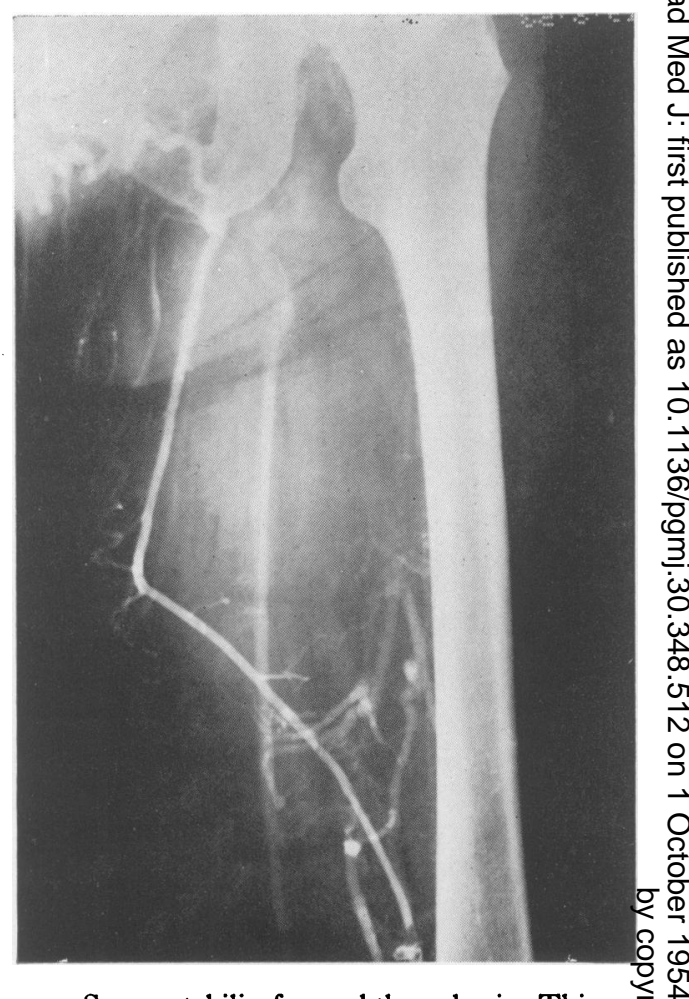

FIG. 9.-Segmental ilio-femoral thrombosis. This vefo gram was done a few days after sudden considerablo swelling of leg, and particularly the upper part of the thigh, occurred, following a long period of squatting on the grass watching a cricket matck with the thigh fully flexed. Note how the dee? veins end at mid-thigh and the venous reture from the leg is by the saphenous (the straight vessel and its postero-medial tributary (the L-shapeo vessel). Note also the tortuous collateral externaf pudendal veins.

sequelae from the next group of deep thromboses which start in the calf. This ilio-femoral type of segmental thrombosis is much rarer than the next variety; clinically it is characterized b. sudden circumferential painful swelling ancs oedema of the leg which is most marked in the thigh; within two or three days numerous smalp veins coursing over the inguinal ligament in fronts and up round the fold of the buttock behind maketheir appearance-these are the collateral veinser The whole condition may subside within a month (if not due to a local malignant condition) an\& leave practically no sequelae. As the thrombosis has not involved the deep veins of the lower leg it is not followed by the ulcer and induration syne drome. (2) Calf thrombosis (Fig. 10). This is by far the commonest variety. The thrombosis starts in the large venous sinuses of the calf (already reo ferred to in the section of anatomy), spreads b one or more of the numerous veins draining soleuङ 

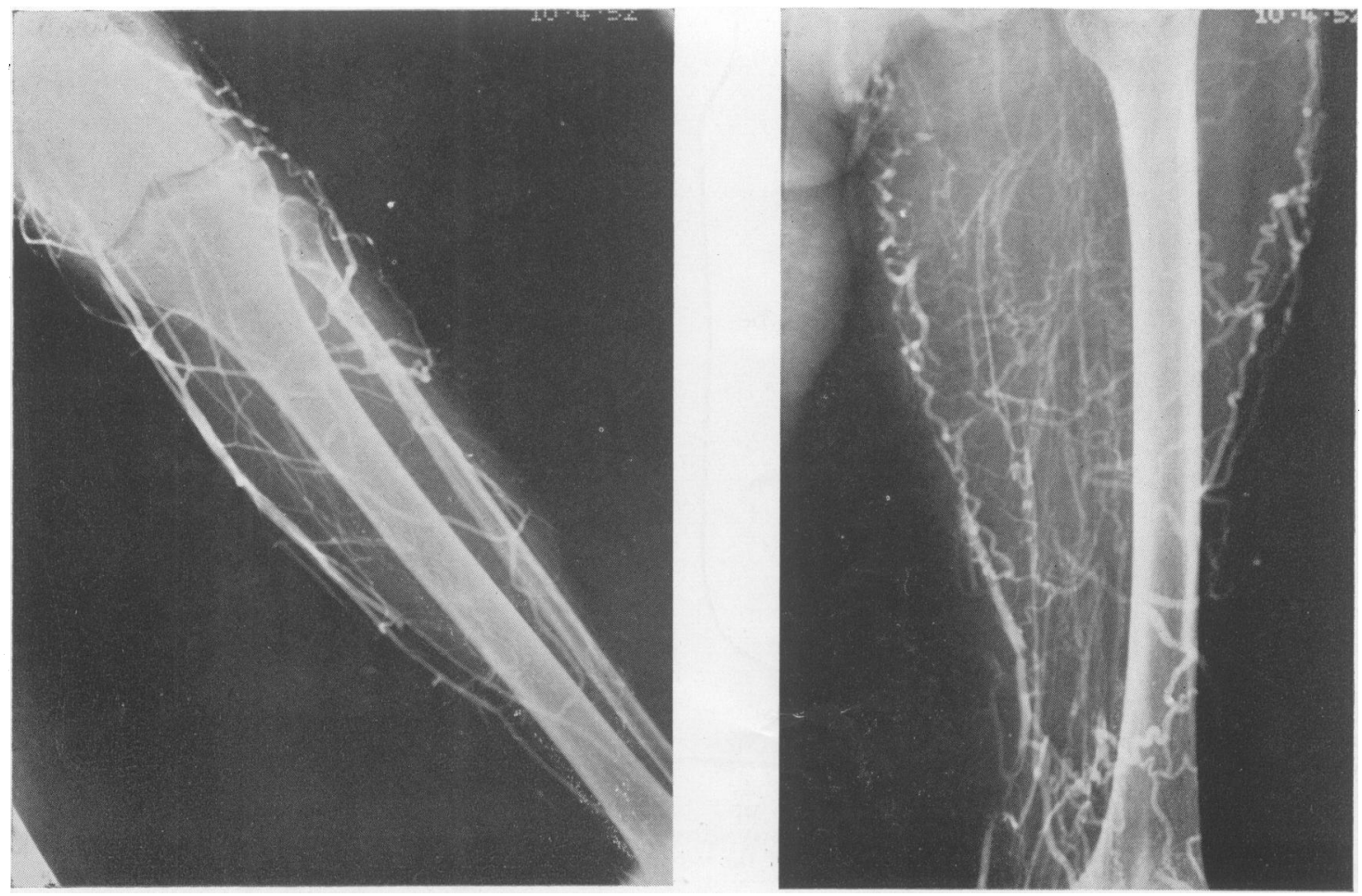

Fig. 10.-White leg or femoral thrombosis. This venogram was done a few days after the development of a typical white leg in a lady of 6o. The upper and lower leg pictures showing the maze of fine venous collaterals, both superficial and deep, are very typical of the early phases of this condition.

into the posterior tibial vein where it may also spread into the perforating veins; it may then spread upwards involving in turn the popliteal, femoral and external iliac vein where it almost always stops where the internal iliac vein joins it. These various stages of spread of the thrombosis are characterized by definite physical signs and clinical picture.

Stage I. Thrombosis confined to calf sinuses:Tenderness in lower third of the calf.

Stage 2. Early spread to posterior tibial:-Some slight oedema at inner side of ankle and localized tenderness over the sites of the middle and/or upper perforating veins. The leg may feel warm.

Stage 3. Extensive involvement of posterior tibial veins and/or peroneal veins:-Obvious oedema of ankle and increase in diameter of calf. The leg and calf is warm. Fever up to $100^{\circ} \mathrm{F}$.

Stage 4. Spread to popliteal vein:-Considerable oedema of ankle and increase in size of calf. Fever.

Stage 5. Spread to femoral and iliac veins:Classical picture of 'white leg.' Concentric swelling and tense oedema of whole leg and thigh. Leg is pale or slight dusky blue and is hot to the touch. Fever up to $\mathrm{IOI}^{\circ} \mathrm{F}$.

\section{The Factors Responsible for Development of Calf Thrombosis}

These factors may be grouped under local and general.

\section{Local Factors}

The most important single factor is stasis. In the section on physiology it was noted that when the legs are below the level of the heart and the calf is at rest the venous flow in the leg is extremely sluggish and, in fact, blood pools in the calf. This is a common factor with any patient ill in bed from whatever cause. The other local factor is possibly trauma to the calf while under the anaesthetic on the operating table.

\section{General Factors}

There are certain general factors predisposing to increased coagulability of the blood in disease. These include increased viscosity (polycythaemia and dehydrated states), increased platelet count (post-operative and post-partum). There is also the undoubted fact that in certain cases of cancer (especially of the lung and pancreas) there is an increased tendency to thrombosis, the cause of which is so far unexplained. 


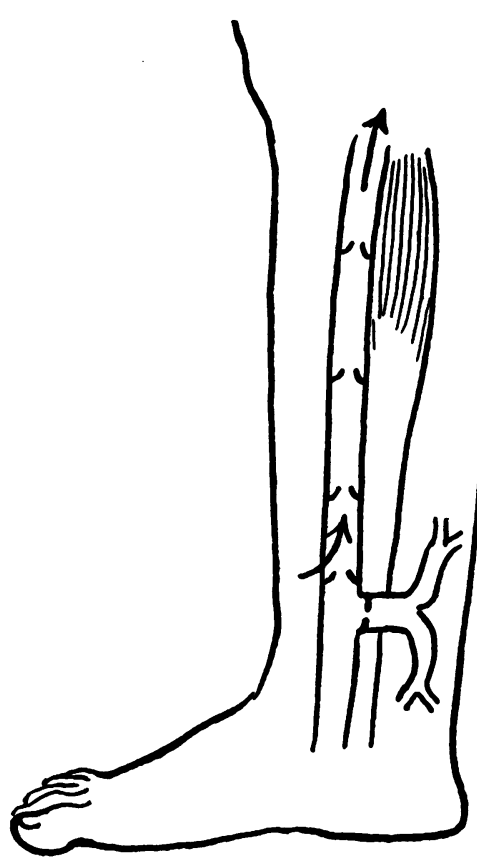

I

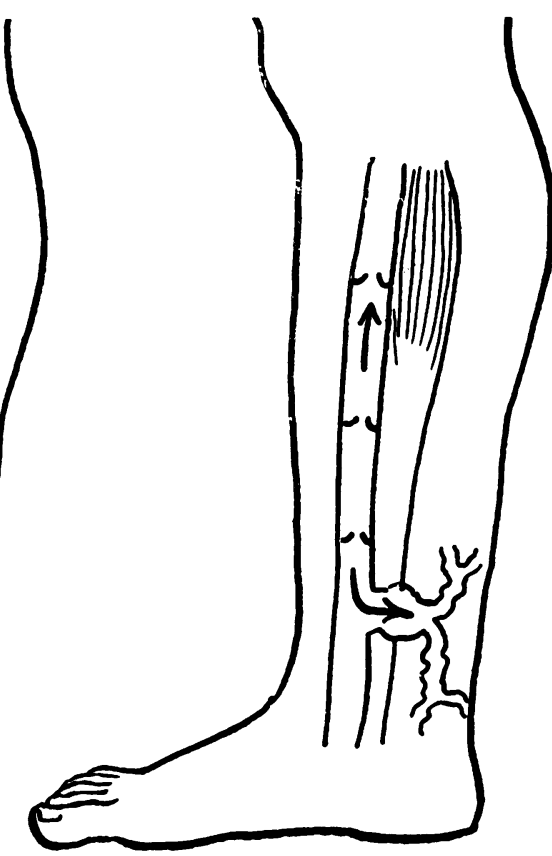

2

Early effect

FIG. I1.-Diagram of the effects of destruction of the valve in one of the large direct ankle perforating veins.

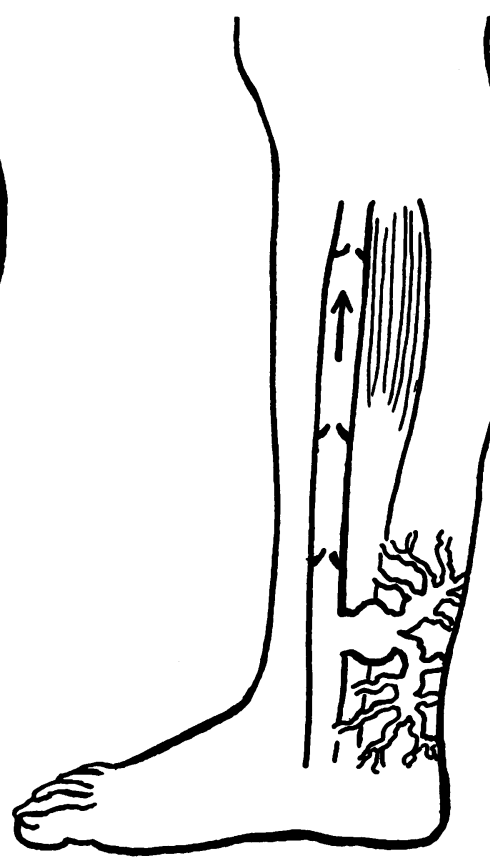

3
It follows from this consideration that the most powerful weapons in the prevention and treatment of this form of thrombosis are elevation of the legs and the encouragement of calf movements. The use of anticoagulants is of entirely secondary importance to the above measures.

Calf thrombosis is nearly always bilateral, although the signs on one side may be considerably in advance of those on the other.

It is not proposed to discuss the question of embolism in this paper.

\section{The Sequelae of Thrombosis}

The three main sequelae of thrombosis may be:-

Chronic oedema of the leg and ankle.

Induration, pigmentation and ulceration of the lower third of the leg, the ' gaiter area.' leg.

Gravitational pain and aching in the calf and

Two rarer sequelae are:-(I) A contracture of the soleus leading to an acute equinus deformity of the foot. The tendo achillis may become so short, due to this contracture, that the patient cannot put her heel to the ground and cannot wear low heeled shoes. (2) A hypertrophy and increase in girth of the upper part of the calf (probably due to chronic intramuscular oedema) giving the appearance of ' well-developed calves' and usually associated with gravitational pain and aching.
These sequelae may appear all together or ome or two may occur without the others. Moreover there is a characteristic latent period before the most dreaded sequelae-induration and ulceration $\frac{}{\circ}$ -appear. Many authors (Homans, Linton, ֶֻ Hojensgard and Cockett) have pointed out that $\stackrel{\square}{\square}$ the peak incidence of ulceration and induration is $\overrightarrow{\vec{A}}$ about two years after the episode of thrombosis. $\frac{0}{3}$ This now becomes understandable if we consider? the effect of thrombosis on the physiology of the calf pump and venous return.

The first important point is that once thrombosis 3 . has occurred in a vein recanalization is the ruleo (Buxton and Collar, 1945; Linton and Hardy, 1947; Dow, 195I; Cockett, 1953). This re-ô canalization starts within a few weeks as fine blood₹ channels growing into the clot which graduallyo coalesce forming one or more large channels which $>$ may be as big as the original vein or bigger.․ㅡ․ Another way in which recanalization may occur is by retraction of the clot to the side of the vein and then gradual organization. In either case the re- $N$ sult is that the venous valves are destroyed. In the average case this process is complete and leaveso effective large valveless deep channels in from oneo to two years. It is from this time onwards that the severe sequelae appear. Now it has been noted $\stackrel{\text { ? }}{?}$ that as the thrombosis spreads from calf to posterior tibial veins it also involves the perforating $\frac{\vec{\Phi}}{\mathbb{T}}$ veins (Cockett and Jones, 1953). Thus when re- 


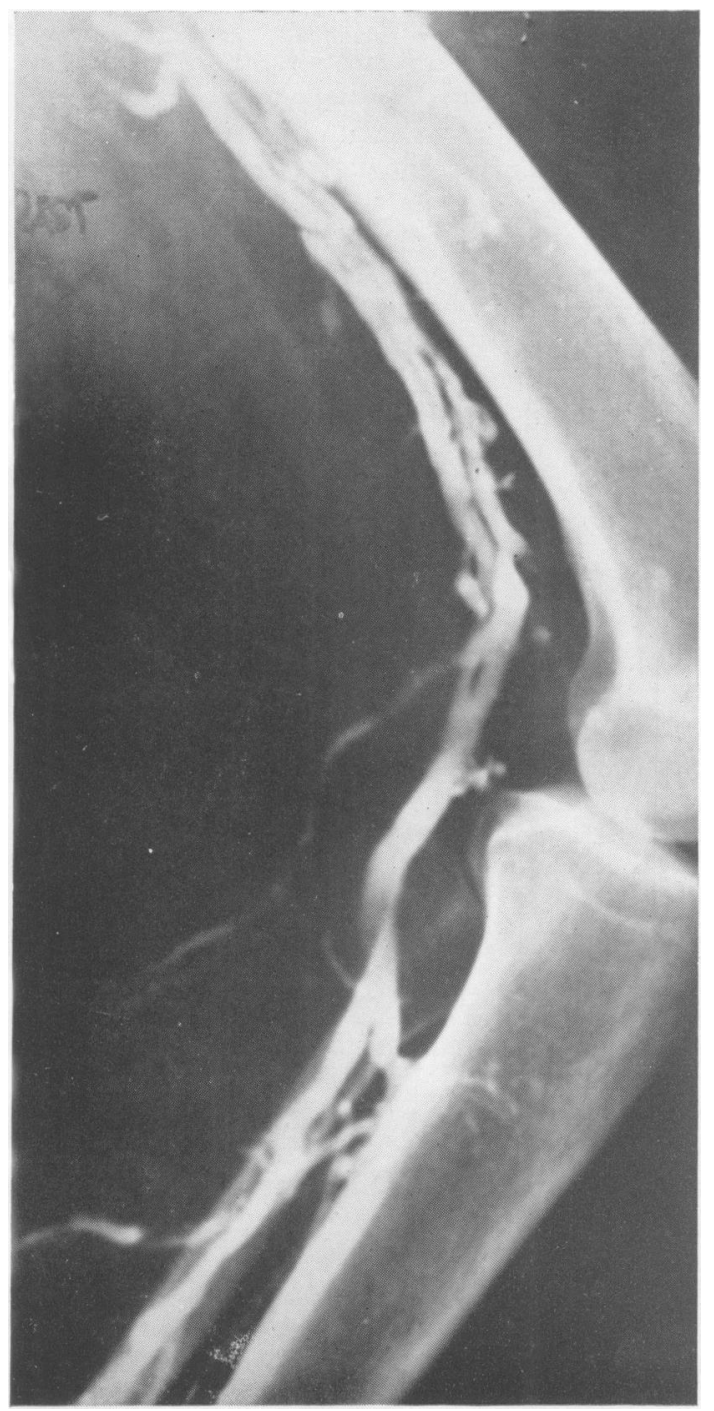

Fig. 12.- $A$ Recanalized Deep Vein. The patient had had a post partum white leg eight years previously and she now had a small post-malleolar ulcer. No superficial varicose veins were present. This patient had the deep vein tied in Hunter's canal and the next figure shows the appearance of the vein in cross-section.

canalization occurs not only are the valves in the deep veins destroyed but also the valves of the large direct perforating veins in the lower leg (see Figs. 6 and 7). These veins may then be regarded as 'leaks' in the lower part of the calf pump, where the rise of pressure within the pump is greatest on contraction. The effect on the subcutaneous tissues is shown diagrammatically in Fig. II.

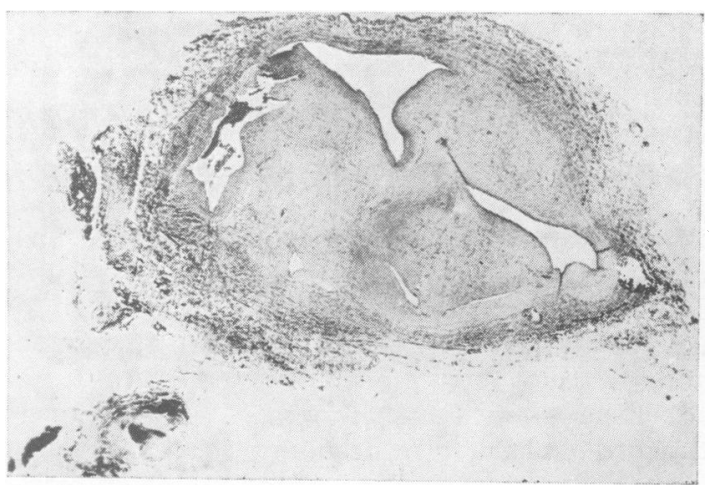

FIG. 13.-Cross-section of a recanalized femoral vein. This is the same patient as in Fig. 12.

Thus the essential and basic pathological physiology in the lower third of the leg is an unrelieved venous hypertension of the veins and venules of the subcutaneous tissues. These veins are fine and thin walled and are not intended to stand up against a venous pressure of $90 \mathrm{~mm}$. $\mathrm{Hg}$. indefinitely, so they gradually dilate. This sustained subcutaneous venous hypertension, unrelieved by exercise of the calf, has been demonstrated by many authors measuring the changes in venous pressure in veins of the foot on exercise in cases of the post-thrombotic syndrome.

It is thus apparent that the well known sequelae of deep thrombosis, induration, ulceration and oedema are primarily due to destruction by thrombosis of the valve system within the calf pump. Destruction of valves in the whole popliteal and femoral system is not further contributory towards this induration and ulceration. However, such patients with complete destruction of valves in popliteal and femoral veins do often have more oedema and more postural aching and pain in the calf than people who have had calf thrombosis alone (see Figs. I2 and I3). This is particularly so if their occupation is one which necessitates heavy labour in the erect position. Such muscular effort causes a repeated rise in intra-abdominal pressure which is transmitted straight down the large valveless deep channel to the lower leg causing increased oedema and a deep aching pain in the muscles of the calf (Gunnar Bauer's ' bursting pain'). The classic occupational victim of this is the 'busy housewife.'

\section{Treatment}

This brings us to a consideration of the treatment of these sequelae of thrombosis. Prevention is better than cure and the most essential point therefore is the prophylaxis of post-operative and post-partum thrombosis. 
Once the post-thrombotic syndrome has been established some regime of management is necessary. As the basic aberration in this disease is a persistent venous hypertension in the subcutaneous tissues round the ankle and malleoli, the most necessary part of treatment is the application of strong elastic pressure from outside which supports and compresses the whole of the subcutaneous tissues and allows a massaging action to take place between deep muscles and elastic support. Such a system, to some extent, restores the efficiency of the calf pump. In the more advanced cases a firm webbing elastic bandage applied over a dressing or cotton bandage, carefully moulded round the malleoli and continued up to just below the knee is required. This is put on before rising and discarded at night. The patient is instructed to sleep with the foot of the bed slightly raised. This simple regime, combined with local massage in advanced cases, will heal most post thrombotic ulcers and relieve most of the pain and control the oedema. When the ulcers are healed a strong elastic stocking can be substituted. (Elasto net stockings are useless for this purpose as they are not strong enough.) The great advantage of this form of treatment is that it is ambulatory and does not interfere with the patients' life or work.

Another simple way of lowering the venous pressure in the legs is to put the patient to bed with the feet above the level of the heart. Under such circumstances venous ulcers rapidly heal. When they get up again support is vitally necessary to prevent breaking down.

Local applications to ulcers are unimportant except that gross local surface infection must be controlled (lotio streptomycin $\mathrm{I} / \mathrm{I}, 000$ is best for this) and substances which induce irritation of the sensitive skin in these cases must be avoided. (This includes the penicillin creams, eusol used for a long time, and flavine.) Zinc cream is the safest local application.

\section{Surgical Treatment}

Surgical treatment must be looked upon as an episode in the general management of these cases. In older patients and those who are infirm from any other reason conservative management with the bandage routine is usually preferred. However, there is a large group of younger people (under the age of 50) who are anxious to undergo surgical treatment to get rid of their ulcers and other symptoms and to stop them getting worse.

The surgical treatment of a venous ulcer entails first a careful evaluation of which group of veins are at fault. Ulcers associated with gross and obvious incompetence of the great or small saphenous systems should have these superficiat veins ablated. This is so whether there is a histon of past deep thrombosis or not, as incompetent superficial veins are an encumbrance to the super ficial circulation in any case.

Most ulcers (even those associated with super ficial venous incompetence) are essentially pos thrombotic in origin and the essential lesion under lying them is destruction of the valves in the pes forating veins of the lower third of the leg. The operative treatment of these ulcers by the exposure and ligation of these veins is undergoing trial in this country and America and is giving extremel $\not / \not$ promising results (Linton, 1953; Wright, 1954 Cockett, 1953).

Finally, the much discussed operation of deep. venous ligation (femoral or popliteal) must be appraised. From several follow-up studies nowe published (Cockett, I953; Boyd, I954; Goligherpo 1953; Moore, 1953; Linton, 1953) it is now apparent that deep venous ligation alone has little effect on ulcers. The early glowing reports of Bauer have not stood the test of time. But this is not to be wondered at because, as we have seen from the foregoing considerations, the essentia pathology of ulceration and induration is all in the calf itself.

However, the effect of ligation of large competent deep venous trunks on gravitatiōi calf pain is marked and definite. All auth appear to be agreed on this. In performing this operation for pain, however, it is most essential be sure that it is being done for the right sort of pain. Most patients with recent ulceration of the leg have pain and aching on standing up and the pain is in the lower third of the leg and in the ulcer The true generalized aching of the calf muscles as the day wears on is a much rarer complaint. Deep venous ligation should not be contemplated unt it has been shown that a reasonable period of conservative treatment (say six months) which heas the ulcer, does not abolish or ease the calf pain It must then be demonstrated, by a reliable venos graphic technique, that the deep vein is in fact large, valveless and pathological (Gryspeerdt and Cockett, 1953). In such circumstances ligation the deep vein (either popliteal or femoral) wi bring relief and a grateful patient (especially if the patient has to be on his or her feet all dayno Ligation of such recanalized incompetent deep veins has very little effect on the amount off swelling present, neither increasing nordreasin gee it.

Sympathectomy alone does not control venow ulceration or any of the symptoms, but it is useful adjunct to appropriate venous ligation in the erythrocyanoid type of leg.

Bibliograthv contimued on haoe 512 
BOCKUS, H. L. (1943), 'Textbook of Gastro-Enterology,' Vol. I, Philadelphia and London.

BOCKUS, H. L. (I944), Ibid., Vol. II.

FRAZER, A. C., FRENCH.'J. M., and THOMPSON, M.D.

(1949), Brit. F. Radiology, 22, 123. . (1952), Lancet, ii, 356.

GLAZEBROOK, A. J. (1952), Ibid., i, 895 .

GOLDEN, R. (I945), Radiological Examination of the Small Intestine,' Philadelphia and London.

GOLDEN, R. (1950), Brit. F. Radiology, 23, 390.

GRACE, W. J., WÖLF, S., and WOLLFF, H. G. (1951), "The Human Colon,' New York and London.

HALL, S. B. (1949), 'Psychological Aspects of Clinical Medicine,' London.

HARDY, T. L. (1934), Clin. $\mathfrak{F} ., 63,407,453$.

HARDY, T. L. (1945), Lancet, i, 5 I9, 553 .
HURST, A. F. (1911), Ibid., i, 1051, $1119,1187$.

JORDAN, S. M., and KIEFER, E. D. (1929), Ұ.A.M.A., 93, 592.

JORDAN, S. M. (1932), Ibid., 99, 2234.

MACPHEE I. W. (1053), Lancet, i, 678 .

POSEY, E. L., and BARGEN, J. A. (195I), Amer. F. Med. Sciences,

RAY, B. R., and NEILL, C. L. (1947), Annals of Surgery, 126, 709.

RYLE, J. A. (1928), Lancet, ii, III5.

RYLE, J. A. (1931), L.ıncet, i, 737.

SPRIGGS, E. I. (I93I), Q.F.M., 24, 533 .

WILSON, T. S. (1927), 'Tonic Hardening of the Colon,' London.

WOLF, S. G., and WOLFF, H. G. (1947), 'Human Gastric Function,' 2nd edition, New York.

YOUMANS, W. B. (I949), ' Narvous and Neurohumorel Regulation. of Intestinal Motility.' New York.

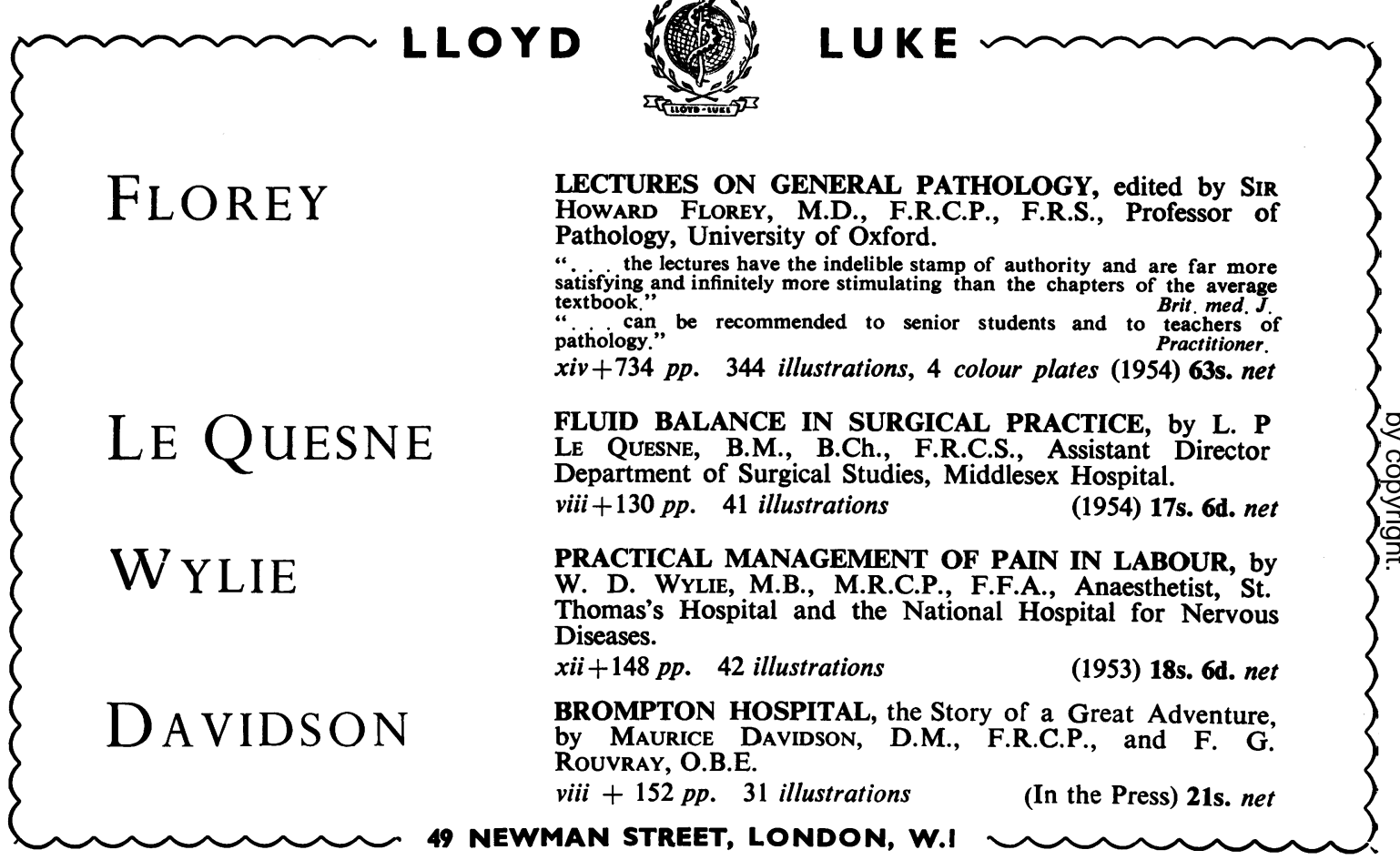

Bibliography continued from page $522-F$. B. Cockett, M.S., F.R.C.S.

\section{BIBLIOGRAPHY}

BARCROFT, H., and DORNHORST, A. C. (1948), f. Physiol., I08, 39.
BAZMAIIAN (1952), Surg. Gynae. Obst., $95,537$.

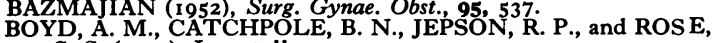
S.' S. (1953), Lancet, ii, $\mathrm{I}_{3}$.

BUXTON, R. W., and COLLER, F. A. (1945), Surgery, 18, 663.

COCKETT, F. B., and ELGAN-JONES, D. E. (1953), Lancet, i, 17.

CKETT, F. B. (I953), 'Pathology and Treatment of Venous Ulcers of the Leg,' MS. Thesis, London.

DOW, J. D. (195I), F. Fac. Radiol., 2, 180.

EGER, S. A., and CASPER, S. I. (1943), f. Amer. med. Ass., 123, 148.

GAY, J. (1868), ' On Varicose Disease of the Lower Extremities and its Allied Disorders,' Churchill, London.

GAY, J. (1867), Lettsomian Lectures.

GOLIGHER, J. C. (1953), Lancet, i, 96.

GRYSPEERDT, G., and COCKETT, F. B. (1953), Brit. $\mathcal{F}$ Radiol., 26, 329.

HOJENSGARD, I. C., and STURUP, H. (1949), Acta. Chir. Scand., 99, 133.
HOJENSGARD, I. C., and STURUP, H. (1952), Acta. Physiol. Scand., 27, 49.

HOMANS, J. (1916), Surg. Gynae. Obst., 22, 143.

HOMANS, J. (1917), Ibid., $24,300$.

LINTON, R. R., and HARDY,, I. B. (1948), Surgery, 24, 452.

LINTON, R. R.'(1953), Ann. Surg., Sept.

LUKE, J.'L. (1951), Surgery, 29, $38 \mathrm{I}$.

MCLACHLIN, J., and PATERSON, J. C. (195I), Surg. Gynae.

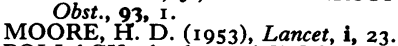
POLLACK, A. A., and WOOD, E. H. (1949), F. Appl. Physiol.,

POWELL, T., and LYNN, R. B. (195I), Surg. Gynae. Obst., WALK, 953 . WARREN, R., WHITE, E. A., and BELCHER, C. D., (1949),

Surgery, 26, 435 .
WARWICK, W. T. (1931), ' The Rational Treatment of Varicose Veins and Varicocele,' Faber, London. WELLS, H. S., YOUMẢNS, J. B., and MILLER, D. G. (1938),

WRIGHT, H. PAYLING (1952), Brit. med. Bull., 8, 187.

WRIGHT, H. PAYLING (1952), Brit. Heart. F., 14, 325.

WRIGHT, R. B. (I953), Lancet, ii, 1273. 